\title{
Raman spectroscopic evidence for the inclusion of decanoate ion in trimethyl- $\beta$-cyclodextrin
}

\author{
Ana Filipa Seiça, Luís A.E. Batista de Carvalho, M. Paula M. Marques, José J.C. Teixeira Dias* \\ Research E' Development Unit “Química-Física Molecular”, University of Coimbra, 3004-535 Coimbra, Portugal
}

\section{A R T I C L E I N F O}

\section{Article history:}

Received 1 February 2016

Received in revised form 20 April 2016

Accepted 20 April 2016

Available online 30 April 2016

\section{Keywords:}

External intensity standard

Solvent subtraction

Decanoate ion

$\beta$-Cyclodextrin

Trimethyl- $\beta$-cyclodextrin

Micelles

\section{A B S T R A C T}

A method for calibrating Raman intensities of diluted aqueous solutions, based on the integrated intensity of the $\mathrm{OH}$ stretching bands of liquid water as an external intensity standard, is described and used to obtain a difference spectrum that reveals intensity changes mainly due to the intermolecular interaction between two solutes. The method is applied to trimethyl- $\beta$-cyclodextrin in sodium decanoate aqueous solutions. The difference between the interaction spectra above and below the critical micellar concentration of sodium decanoate, in the $\mathrm{CH}$ stretching region between 2700 and $3100 \mathrm{~cm}^{-1}$, shows an intensity increase of the $\mathrm{CH}$ stretching bands for trimethyl- $\beta$-cyclodextrin above the critical micellar concentration of sodium decanoate, whereas $\beta$-cyclodextrin is relatively insensitive to the presence of decanoate ion micelles in aqueous solution.

(c) 2016 Elsevier B.V. All rights reserved.

\section{Introduction}

Cyclodextrins (CDs), doughnut-shaped cyclic oligomers formed by $(\alpha-1,4)$-linked $\alpha$-D-glucopyranose units, are well known for their ability to include apolar molecules or apolar molecular fragments that fit in their cavities [1-3]. Inclusion complexation by natural CDs involves guest-host interactions that depend on several factors like the $C D$ ring size and guest size, van der Waals interactions, release of water molecules, hydrogen-bond formation and hydrophobic interactions [4].

Methylation changes the physical and chemical properties of CDs. In particular, methylated $\mathrm{CDs}$ have negative solubility coefficients in water, that is, they are well soluble in cold water and slightly soluble in hot water where they usually precipitate or crystallize $[5,6]$. At $25^{\circ} \mathrm{C}$, the solubility of trimethyl- $\beta$-cyclodextrin (TRIMEB; $31 \mathrm{~g} / 100 \mathrm{~mL})$ is ca. 17 times the solubility of $\beta C D(1.85 \mathrm{~g} /$ $100 \mathrm{~mL}$ ) [7]. In addition, the inclusion properties of methylated CDs are generally improved over those of natural CDs, as the complexes of methylated CDs in solution are more stable than those of natural species [4]. Due to steric hindrance involving methyl groups and the lack of intramolecular hydrogen bonds, trimethyl-CD macrocycles become distorted and their potential to discriminate chiral molecules increases as the complex formation induces conformational changes of the host molecule to suitably accommodate the guest within the CD cavity [8-13].

It has been shown by small-angle neutron scattering (SANS) that ammonium decanoate in $\mathrm{D}_{2} \mathrm{O}$ solution originates spherical micelles $[14,15]$. Analysis of ${ }^{1} \mathrm{H}$ NMR chemical shift variations of the methyl protons of sodium decanoate in $\mathrm{D}_{2} \mathrm{O}$ solutions leads to a critical micellar concentration (CMC) approximately equal to $116 \mathrm{mM}$ and points to a narrow distribution of sizes about the mean aggregation number for decanoate ion micelles [16]. When a cyclodextrin is added to a $200 \mathrm{mM}$ perdeuterated sodium decanoate $\mathrm{NaDec}\left(d_{19}\right)$ solution in $\mathrm{D}_{2} \mathrm{O}(\mathrm{CMC} \approx 116 \mathrm{mM})$, methylated cyclodextrins show correlation peaks in the SANS $I(Q)$ distributions that reflect the degree of methylation, whereas $\alpha C D$ and $\beta C D$ do not originate any correlation maximum [17], a result which seems to exclude the formation of mixed micelles, at least for this surfactant with the above mentioned concentration $[18,19]$.

In this work, the integrated intensity of the complex of Raman $\mathrm{OH}$ stretching bands of liquid water is used as an external intensity standard to normalize the spectra of two solutes (trimethyl$\beta$-cyclodextrin and sodium decanoate) aqueous solutions, and subtract the water spectrum. The resulting normalized spectra are then used to obtain difference spectra that show the interaction between both solutes, above and below sodium decanoate CMC.

\footnotetext{
* Corresponding author.

E-mail address: teixeiradias@ua.pt (J.J.C. Teixeira Dias).
} 


\section{Materials and methods}

\subsection{Materials and samples}

Sodium decanoate (NaDec, Sigma, 98\%), $\beta$-cyclodextrin ( $\beta C D$, Sigma, 97\%) and heptakis (2,3,6-tri-O-methyl)- $\beta$-cyclodextrin (TRIMEB, Cyclolab, 98\%) were used as received without further purification. Milli-Q water was used in the preparation of all solutions and mixtures. All glassware was carefully washed with ethanol and dried before use. Five $\mathrm{ml}$ volumes of $60 \mathrm{mM}$ and $200 \mathrm{mM}$ sodium decanoate solutions were prepared by slow addition of appropriate amounts of sodium decanoate to Milli-Q water, with constant stirring. Each of these solutions was divided in two equal volumes and appropriate amounts of cyclodextrin ( $\beta C D$ or TRIMEB) were added to each of them to obtain solutions $30 \mathrm{mM}$ in the cyclodextrin. Thus, the following aqueous solutions were obtained: $60 \mathrm{mM}$ and $200 \mathrm{mM}$ in sodium decanoate (D60 and $\mathrm{D} 200), 30 \mathrm{mM}$ in the cyclodextrin ( $\beta C D$ or TRIMEB) and $60 \mathrm{mM}$ in sodium decanoate (B30D60 and T30D60), $30 \mathrm{mM}$ in the cyclodextrin and $200 \mathrm{mM}$ in sodium decanoate (B30D200 and T30D200). While the solubility of $\beta C D$ at room temperature in water is $1.85 \mathrm{~g} /$ $100 \mathrm{~mL}$ [7], that is, ca. $16.3 \mathrm{mM}$, its solubility in excess of sodium decanoate is far greater due to the formation of the inclusion complex, thus making possible to prepare the above sodium decanoate aqueous solutions $30 \mathrm{mM}$ in $\beta C D$, at room temperature.

\subsection{Raman spectrometer and dedicated software}

Raman spectra were obtained at room temperature $\left(20-21^{\circ} \mathrm{C}\right)$, with a T64000 triple stage spectrometer in the double subtractive plus spectrograph configuration (focal distance $0.640 \mathrm{~m}$, aperture $\mathrm{f} / 7.5$, holographic gratings of 1800 grooves $\mathrm{mm}^{-1}$ ). A $90^{\circ}$ geometry between the incident radiation and the collecting system was employed. The entrance slit was set to $200 \mu \mathrm{m}$ and the intermediate slit between premonochromator and spectrograph was set to $30 \mathrm{~mm}$. The detection system was a liquid nitrogen cooled non-intensified $1024 \times 256$ pixel $\left(1^{\prime \prime}\right)$ charge coupled device chip. The $514.5 \mathrm{~nm}$ line of an $\mathrm{Ar}^{+}$laser (Coherent, model Innova 300-05) was used as excitation radiation, providing ca. $15 \mathrm{~mW}$ at the sample position. The samples were sealed in Kimax capillary tubes of $0.8 \mathrm{~mm}$ inner diameter. The spectra were collected with an acquisition time of $60 \mathrm{~s}$ for 10 accumulations. Under the above conditions, the error in the determination of frequencies is estimated to be $1 \mathrm{~cm}^{-1}$.

The Raman spectrometer control and data processing were performed using the LabSpec 5.0 (Horiba, France) software. Among other utilities, this software allows to carry out baseline corrections to the spectra, apply a scaling factor to the band
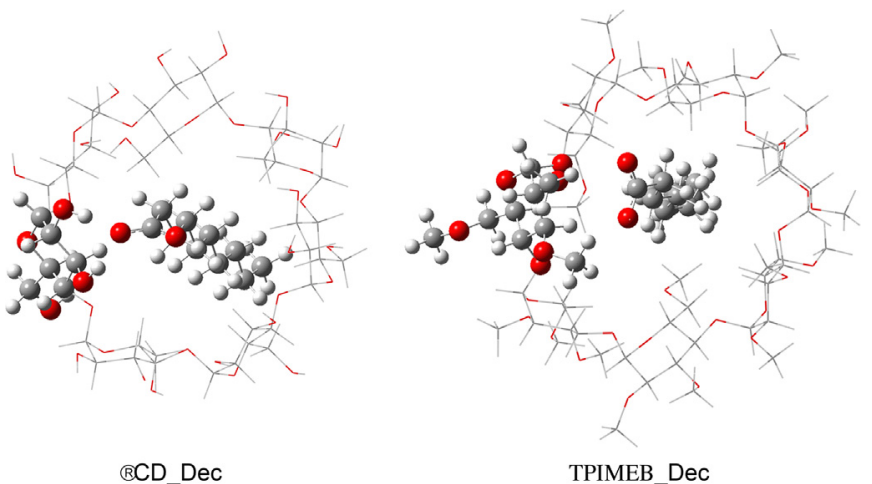

Fig. 1. Optimized geometries for the $1: 1$ inclusion complexes of decanoate ion in $\beta C D$ and in TRIMEB obtained with the Gaussian 09 ONIOM method for two layers (B3LYP/6-31+G(d,p): UFF method).
Table 1

Calculated (scaled) frequencies $\left(\mathrm{cm}^{-1}\right)$ of peak intensities, in the $\mathrm{CH}$ stretching region, for the $1: 1$ inclusion complex of decanoate ion in $\beta C D$ (Glu=glucose unit; $\mathrm{s}=$ symmetric, as = antisymmetric), and observed Raman shifts for the B30D200 spectrum.

\begin{tabular}{lll}
\hline Glu_Dec & approx. description & observed Raman shifts $/ \mathrm{cm}^{-1}$ \\
\hline 2854 & (Glu) $\mathrm{CH}$ & 2856 \\
& & 2875 \\
2889,2907 & (Dec) $\mathrm{CH}_{2} \mathrm{~S}$ & 2902 \\
2918 & (Glu) $\mathrm{CH}_{2} \mathrm{~S}+(\mathrm{Dec}) \mathrm{CH}_{3} \mathrm{~S}$ & 2920 \\
2934 & (Dec) $\mathrm{CH}_{2}$ as & 2939 \\
2951 & (Glu) $\mathrm{CH}+(\mathrm{Dec}) \mathrm{CH}_{2}$ as & \\
2982 & (Dec) $\mathrm{CH}_{3}$ as & 2970 \\
2996 & (Glu) $\mathrm{CH}_{2}$ as & 2999 \\
3005 & (Glu) $\mathrm{CH}$ & \\
\hline
\end{tabular}

intensities of a spectrum, add and subtract data. All spectra were recorded from $300 \mathrm{~cm}^{-1}$ to $3800 \mathrm{~cm}^{-1}$ and a polynomial baseline correction of degree 6 was applied.

In the absence of a dedicated software for processing the Raman spectroscopic data, the interested reader can easily perform all the data processing considered in this paper by using Excel ${ }^{\mathbb{R}}$, provided the recorded spectra can be expressed as a table with two columns, one for the Raman shifts, the other for the corresponding intensities.

\subsection{Frequency calculations}

Frequency and Raman intensity calculations were performed by the system of programs Gaussian 09 [20], with the B3LYP DFT method and the $6-31+G(d, p)$ basis set, the frequencies being scaled by the factor $0.964 \pm 0.023$ [21]. Optimized geometries for the inclusion of decanoate ion in $\beta C D$ and in TRIMEB were treated with the ONIOM method for two layers, the high layer being composed by the decanoate ion and one glucosidic unit of the cyclodextrin and treated at the B3LYP/6-31+G(d,p) level, the low level being taken at the Molecular Mechanics UFF method. In the absence of interglucose hydrogen bonds, TRIMEB shows a somewhat distorted macrocycle (Fig. 1). Tables 1 and 2 present the calculated (scaled) frequencies $\left(\mathrm{cm}^{-1}\right)$ of peak intensities in the $\mathrm{CH}$ stretching region, their approximate descriptions and the observed frequencies.

\subsection{Decomposition of the observed Raman spectra in Lorentzian- Gaussian functions}

Raman spectra between $2700 \mathrm{~cm}^{-1}$ and $3100 \mathrm{~cm}^{-1}$ were decomposed using Mathematica [22] as the linear combination $a$ $L+(1-a) G$, where $L$ and $G$ stand for Lorentzian and Gaussian functions and $a$ represents the fraction of Lorentzian character $(1-a$ is the fraction of Gaussian character). In this fitting, the variable parameters were peak positions, peak intensities, bandwidths (FWHH) and the $a$ parameters. Peak positions were

Table 2

Calculated (scaled) frequencies $\left(\mathrm{cm}^{-1}\right)$ of peak intensities, in the $\mathrm{CH}$ stretching region, for the 1:1 inclusion complex of decanoate ion in TRIMEB ( Tmg = trimethylglucose unit; $s=$ symmetric, as =antisymmetric), and observed Raman shifts for the T30D200 spectrum.

\begin{tabular}{lll}
\hline Tmg_Dec & approx. description & observed Raman shifts $/ \mathrm{cm}^{-1}$ \\
\hline 2857 & $(\mathrm{Tmg}) \mathrm{CH}_{3} \mathrm{~S}$ & 2857 \\
2882,2889 & $(\mathrm{Tmg}) \mathrm{CH}_{2} \mathrm{~s},(\mathrm{Dec}) \mathrm{CH}_{2} \mathrm{~s}$ & 2889 \\
2902 & $(\mathrm{Tmg}) \mathrm{CH}_{3}+(\mathrm{Dec}) \mathrm{CH}_{2} \mathrm{~s}$ & \\
2917,2927 & $(\mathrm{Dec}) \mathrm{CH}_{2} \mathrm{~S}$ & 2931 \\
2935,2948 & $(\mathrm{Dec}) \mathrm{CH}_{2}$ as & 2943 \\
2953,3053 & $(\mathrm{Tmg}) \mathrm{CH}$ & \\
2982 & $(\mathrm{Dec}) \mathrm{CH}_{3}$ as & \\
3009,3013 & $(\mathrm{Tmg}) \mathrm{CH}_{3}$ as & 3008 \\
\hline
\end{tabular}



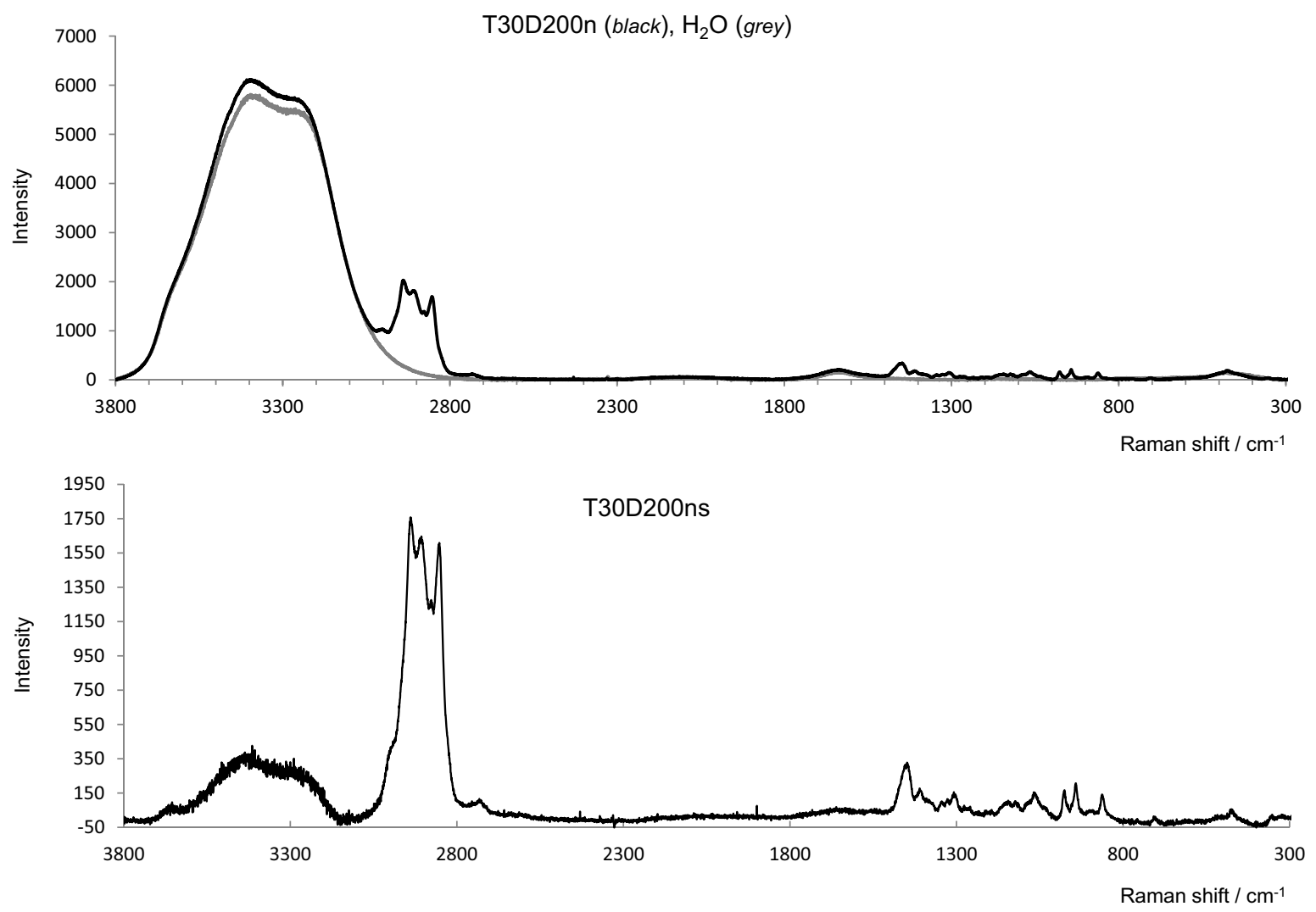

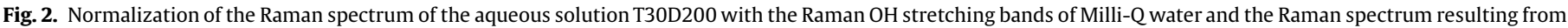
the subsequent subtraction of the Raman spectrum of Milli-Q water (T30D200 ns).

initially set by trial and error, followed by the fitting of bandwidths and peak intensities. The $a$ parameters were fitted at last.

\section{Results and discussion}

\subsection{The Raman $\mathrm{OH}$ stretching band of water as an external intensity} standard

The Raman spectrum of liquid water has been the subject of a number of previous studies [23-27]. In particular, the feature between $300 \mathrm{~cm}^{-1}$ and $1000 \mathrm{~cm}^{-1}$ with maximum at ca. $470 \mathrm{~cm}^{-1}$ is composed by three active intermolecular librational modes [23]. In turn, the $\mathrm{HOH}$ bending feature, whose maximum occurs nominally at $1640 \mathrm{~cm}^{-1}$, has a slightly asymmetric band shape [23]. At last, the bands between $2700 \mathrm{~cm}^{-1}$ and $3800 \mathrm{~cm}^{-1}$ are assigned to the $\mathrm{OH}$ stretching modes [25-27].

In diluted aqueous solutions, at ambient temperature, water concentration is approximately equal to $55.5 \mathrm{~mol} \mathrm{dm}^{-3}$, as the densities of diluted aqueous solutions do not appreciably depart from the density of pure water approximately given by $1.00 \mathrm{~g} \mathrm{~cm}^{-3}$ [28]. Therefore, the solvent concentration greatly exceeds the solute concentration and the Raman bands of water that correspond to group frequencies (the $\mathrm{HOH}$ bending and the $\mathrm{OH}$ stretching bands) can in principle be used as external standards to normalize the spectrum of a diluted aqueous solution. In particular, the $\mathrm{HOH}$ bending band is exclusively associated with the water

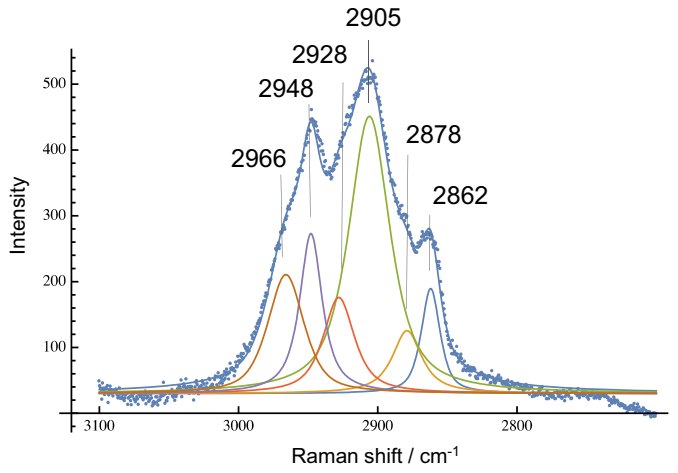

$\Delta \mathrm{B} 30 \mathrm{D} 200$

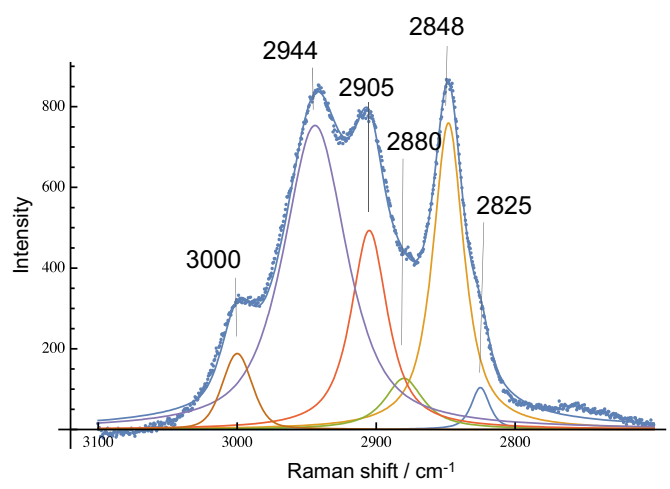

$\Delta$ T30D200

Fig. 3. Decomposition in Lorentzian-Gaussian band profiles of the $\Delta \mathrm{B} 30 \mathrm{D} 200$ and $\Delta \mathrm{T} 30 \mathrm{D} 200$ Raman spectra in the Raman $\mathrm{CH}$ stretching wavenumber region. 
solvent. However, this is a very weak, broad and asymmetric band, sometimes lacking a well defined baseline due to interference with nearby Raman and fluorescence bands. Hence, its use as an external intensity standard can lead to appreciable errors. In turn, the $\mathrm{OH}$ stretching bands of liquid water are very strong and can be used in principle as an external intensity standard for normalization of Raman spectra of diluted aqueous solutions. The use as an external rather than internal intensity standard allows subtracting the water spectrum, thus obtaining the $\mathrm{CH}$ stretching region free from the interference with the nearby wing of the $\mathrm{OH}$ stretching bands, and allows obtaining difference spectra to reveal the interaction between two solutes. The $\mathrm{OH}$ stretching bands of water have been previously used as internal standard in a number of studies ([29-31]) to determine the concentration of various chemical species in aqueous solutions. In addition, several methods for calibrating Raman intensities have been described [32] and a comprehensive review of photometric standards for Raman spectroscopy can be found in [33].

\subsection{Equilibrium concentrations}

The aqueous solutions B30D60, B30D200, T30D60 and T30D200 have the cyclodextrin and decanoate ion in dynamic equilibrium with the inclusion complex. Conservation of the total cyclodextrin and decanoate concentrations is expressed by the following relationships

$[\mathrm{CD}]_{\mathrm{t}}=[\mathrm{CD}]+\left[\mathrm{CD}_{\mathrm{D}}\right]$

$[\mathrm{D}]_{\mathrm{t}}=[\mathrm{D}]+\left[\mathrm{CD}_{\mathrm{D}}\right]$

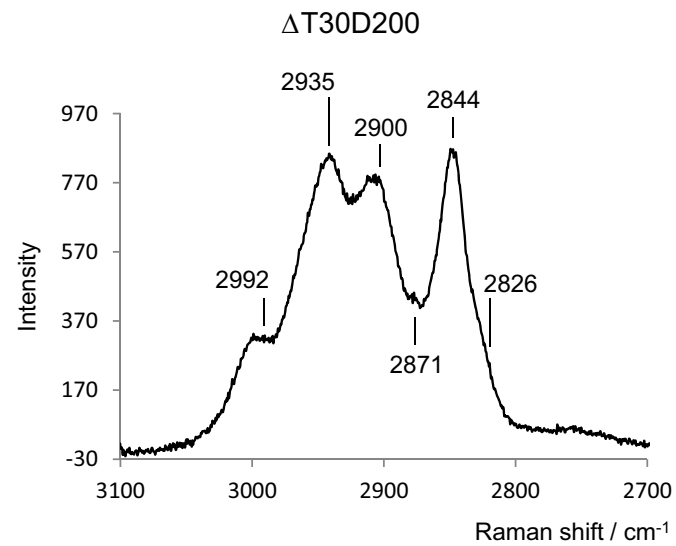

where

$\left[\mathrm{CD}_{\mathrm{D}}\right]=K[\mathrm{D}][\mathrm{CD}]$

and $K$ represents the binding inclusion constant, [D] stands for the decanoate concentration in solution and in the micelles (there are equilibria involving these concentrations) and [CD_D] represents the concentration of the 1:1 inclusion complex. For B30D60 and T30D60, $[C D]_{t}=30 \mathrm{mM}$ and $[D]_{t}=60 \mathrm{mM}$, whereas for B30D200 and T30D200, $[C D]_{t}=30 \mathrm{mM}$ and $[D]_{t}=200 \mathrm{mM}$.

For the decanoate ion inclusion in $\beta C D$, the following binding constants have been reported: $3.7 \times 10^{3}$, by affinity capillary electrophoresis [34], $2.6( \pm 0.2) \times 10^{3}$, by spectral displacement method [35], and $7.5( \pm 0.9) \times 10^{3}$, by potenciometry [36]. Any of these $K$ values yields [ $\left.\beta C D \_D\right] \approx 30 \mathrm{mM}$, as there is an excess of decanoate over cyclodextrin, $[\beta C D] \approx 0, \quad[D] \approx 30 \mathrm{mM}$ for B30D60 and $[D] \approx 170 \mathrm{mM}$ for B30D200. For the decanoate ion inclusion in TRIMEB, a binding constant value could not be found in the literature. However, using trial $K$ values equal to $10^{i}(i=1-4)$, the concentration values are approximately the same as those found for the $\beta C D$ aqueous solutions, that is, [TRIMEB_D] $\approx 30 \mathrm{mM}$, $[$ TRIMEB $] \approx 0,[D] \approx 30 \mathrm{mM}$ for $\mathrm{T} 30 \mathrm{D} 60$ and $[\mathrm{D}] \approx 170 \mathrm{mM}$ for T30D200. Since the cyclodextrin and sodium decanoate aqueous solutions, B30D60, B30D200, T30D60 and T30D200, have an excess of sodium decanoate over the corresponding cyclodextrin, the free cyclodextrin concentrations in solution are negligible.

\subsection{Raman spectra for 1:1 inclusion complexes}

In order to obtain the Raman spectrum due to the $1: 1$ inclusion complex, we need to deal with spectra that share a common intensity

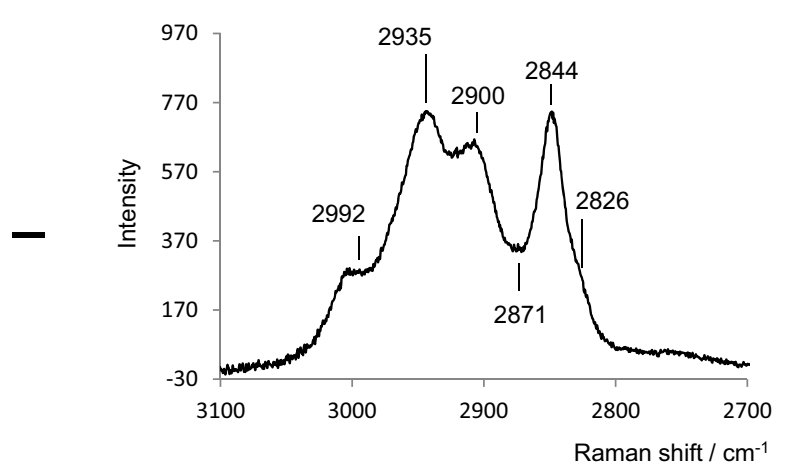

$\Delta T 30 D 200-\Delta T 30 D 60$

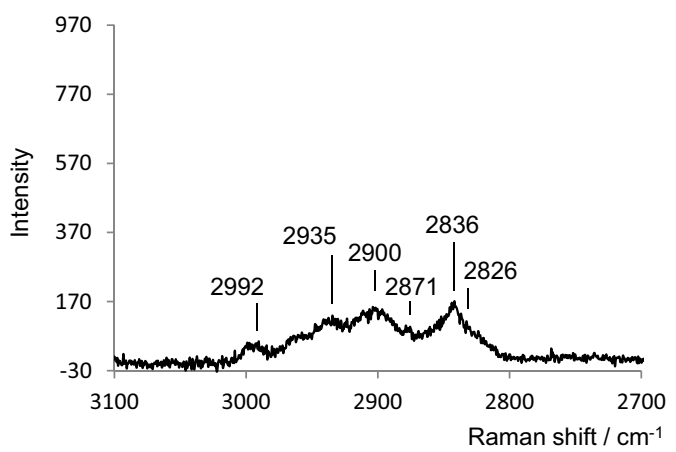

Fig. 4. The Raman spectra $\Delta \mathrm{T} 30 \mathrm{D} 200, \Delta \mathrm{T} 30 \mathrm{D} 60$ and their difference $\Delta \mathrm{T} 30 \mathrm{D} 200-\Delta \mathrm{T} 30 \mathrm{D} 60$ in the $\mathrm{CH}$ stretching region. 
$\Delta \mathrm{B} 30 \mathrm{D} 200$

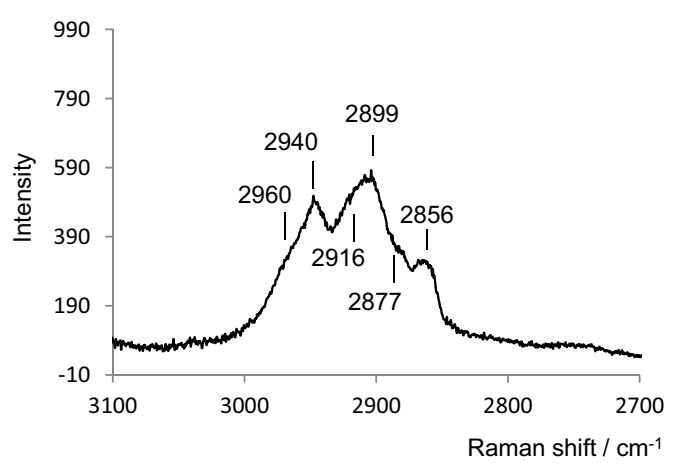

$\Delta \mathrm{B} 30 \mathrm{D} 60$

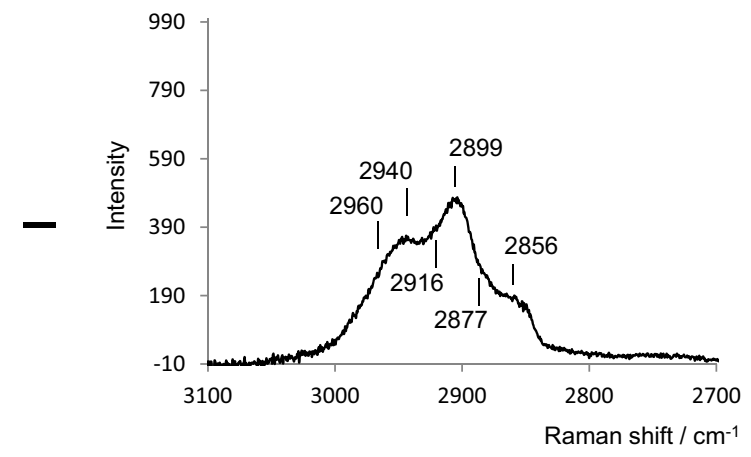

$\Delta \mathrm{B} 30 \mathrm{D} 200-\Delta \mathrm{B} 30 \mathrm{D} 60$

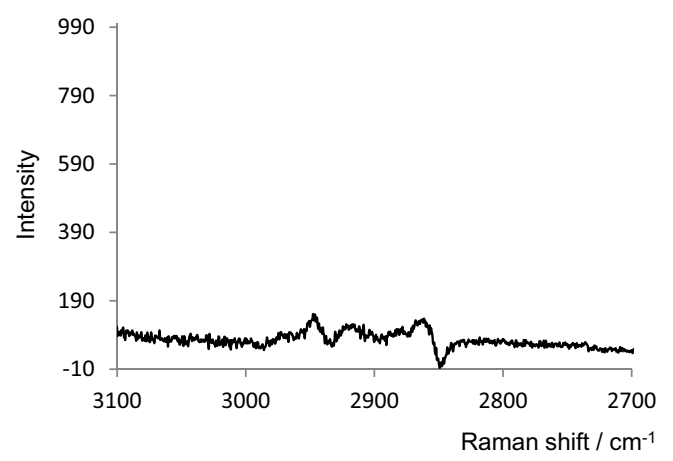

Fig. 5. The Raman spectra $\Delta B 30 D 200, \Delta B 30 D 60$ and their difference $\Delta B 30 D 200-\Delta B 30 D 60$ in the $C H$ stretching region.

scale. To this end, a spectrum is said to be normalized when the profile of its $\mathrm{OH}$ stretching bands matches as closely as possible the corresponding bands of Milli-Q water. Being impossible to obtain a perfect match in all Raman shifts, preference is given to the match on the lower wavenumber wing of this complex of bands, so that $\mathrm{CH}$ stretching bands become free from overlapping with the wing of the $\mathrm{OH}$ stretching bands. After spectral normalization, we can proceed to subtract the water spectrum.

Fig. 2 illustrates the normalization of the T30D200 spectrum and displays the spectrum resulting from water subtraction, which is named T30D200 ns, where " $n$ " and "s" stand for normalization and subtraction of the water solvent. As an order of magnitude of the error involved in the spectral normalization, the integrated intensity of the residual $\mathrm{OH}$ stretching bands in the T30D200 ns spectrum amounts to $4.0 \%$ of the integrated intensity of the complex of the $\mathrm{OH}$ stretching bands of Milli-Q water.

In order to subtract the spectrum corresponding to the excess of decanoate ion present in the T30D200 aqueous solution and obtain the interaction spectrum for the $1: 1$ inclusion complex $\Delta \mathrm{T} 30 \mathrm{D} 200$, we take the following spectral difference $\Delta$ T30D200 $=$ T30D200 ns $-(170 / 200)$ D200 ns, as [TRIMEB_D] $\approx 30 \mathrm{mM}$, [TRIMEB] $\approx 0$ and $[\mathrm{D}] \approx 170 \mathrm{mM}$.

Fig. 3 shows the decomposition of the $\Delta$ B30D200 and $\Delta$ T30D200 spectra in linear combinations of Lorentzian and Gaussian functions. For $\Delta B 30 D 200$, this analysis reveals bands with peak intensities at $2862 \mathrm{~cm}^{-1}, 2878 \mathrm{~cm}^{-1}, 2905 \mathrm{~cm}^{-1}$, $2928 \mathrm{~cm}^{-1}, 2948 \mathrm{~cm}^{-1}$ and $2966 \mathrm{~cm}^{-1}$, while the decomposition of the $\Delta$ T30D200 spectrum exhibits peak intensities at $2825 \mathrm{~cm}^{-1}$, $2848 \mathrm{~cm}^{-1}, 2880 \mathrm{~cm}^{-1}, 2905 \mathrm{~cm}^{-1}, 2944 \mathrm{~cm}^{-1}$ and $3000 \mathrm{~cm}^{-1}$.

Fig. 4 shows the $\Delta$ T30D200, $\Delta$ T30D60 and $\Delta$ T30D200$\Delta$ T30D60 Raman spectra (difference between the 1:1 inclusion complex spectra, above and below the decanoate ion (MC), in the $\mathrm{CH}$ stretching region between $2700 \mathrm{~cm}^{-1}$ and $3100 \mathrm{~cm}^{-1}$. In turn, Fig. 5 comprises the spectra for the $\beta C D$ aqueous solutions, namely, $\Delta$ B30D200, $\Delta$ B30D60 and $\Delta$ B30D200- $\Delta$ B30D60. While the $\Delta \mathrm{T} 30 \mathrm{D} 200-\Delta \mathrm{T} 30 \mathrm{D} 60$ spectrum indicates a significant intensity increase above the sodium decanoate $\mathrm{CMC}$, with respect to the corresponding intensities below the sodium decanoate CMC (Fig. 4), the $\Delta$ B30D200- $\Delta$ B30D60 spectrum shows less significant positive and negative intensity variations (Fig. 5). The different behaviours of TRIMEB and $\beta C D$ in their interaction with sodium decanoate micelles come in line with the previously reported SANS results, where it was found that methylated cyclodextrins show correlation peaks in the $I(Q)$ distributions, whereas $\alpha C D$ and $\beta C D$ do not originate any correlation maximum [17].

\section{Conclusions}

Raman spectra of diluted aqueous solutions are usually dominated by the very intense complex of $\mathrm{OH}$ stretching bands of the water solvent. An aqueous solution containing two weakly interacting solutes $A$ and $B$ yields a spectrum where it may be difficult to identify frequency and intensity variations due to the $A B$ complex of weakly interacting solute molecules. Based on the integrated intensity of the complex of $\mathrm{OH}$ stretching bands of liquid water as an external intensity standard, this paper showed how to obtain a difference spectrum that reveals Raman intensity changes mainly due to the intermolecular interaction between the interacting solutes, provided one knows the equilibrium concentrations of $A, B$ and $A B$ species in aqueous solution. In addition, this method allows to qualitatively distinguish the behaviour of TRIMEB and $\beta C D$ in an aqueous solution of sodium decanoate 
above and below its $\mathrm{CMC}$, in accordance with previously published data on these systems [17].

\section{Acknowledgement}

The authors thank financial support from the Portuguese Foundation for Science and Technology-UID/MULTI/00070/2013.

\section{References}

[1] J. Szejtli, Chem. Rev. 98 (1998) 1743-1754.

[2] W. Saenger, J. Jacob, K. Gessler, T. Steiner, D. Hoffmann, H. Sanbe, K. Koizumi, S M. Smith, T. Takaha, Chem. Rev. 98 (1998) 1787-1802.

[3] K. Harata, Chem. Rev. 98 (1998) 1803-1828.

[4] M.V. Rekharsky, Y. Inoue, Chem. Rev. 98 (1998) 1875-1918.

[5] K. Harata, Recent advances in the X-ray analysis of cyclodextrin complexes, in: J.L. Atwood, J.E.D. Davies, D.D. MacNicol (Eds.), Inclusion Compounds, Inorganic and Physical Aspects of Inclusion, vol. 5, Oxford University Press, 1991, pp. 311-344.

[6] A. Kusmin, R.E. Lechner, M. Kammel, W. Saenger, J. Phys. Chem. B 112 (2008) 12888-12898.

[7] K. Uekama, T. Irie, Pharmaceutical applications of methylated cyclodextrin derivatives, in: D. Duchene (Ed.), Cyclodextrins and Their Industrial Uses, Editions de Santé, Paris, 1987, pp. 395-439.

[8] K. Harata, K. Uekama, M. Otagiri, F. Hirayama, Bull. Chem. Soc. Jpn. 56 (1983 1732-1736.

[9] K. Harata, F. Hirayama, T. Imai, K. Uekama, M. Otagiri, Chem. Lett. 6 (1984) 443 460.

[10] K. Harata, K. Uekama, M. Otagiri, F. Hirayama, Bull. Chem. Soc. Jpn. 60 (1987) 497-502.

[11] K. Harata, K. Uekama, T. Imai, F. Hirayama, M. Otagiri, J. Incl. Phenom. 6 (1988) 443-460.

[12] V. Crupi, G. Guella, D. Majolino, I. Mancini, A. Paciaroni, B. Rossi, V. Venuti, P. Verrocchio, G. Viliani, Philos. Mag. 91 (2011) 1776-1785.

[13] V. Crupi, G. Guella, D. Majolino, I. Mancini, B. Rossi, R. Stancanelli, V. Venuti, P. Verrocchio, G. Viliani, Food Biophys. 6 (2011) 267-273.

[14] S.J. Burkitt, R.H. Ottewill, J.B. Hayter, B.T. Ingram, Colloid Polym. Sci. 265 (1987) 619-627.

[15] R.M. Clapperton, R.H. Ottewill, A.R. Rennie, B.T. Ingram, Colloid Polym. Sci. 277 (1999) 15-24.

[16] C. Andrade-Dias, S. Lima, J.J.C. Teixeira-Dias, J. Colloid Interface Sci. 316 (2007) 31-36.
[17] S. Andrade-Dias, J.J.C. Teixeira-Dias, J. Teixeira, J. Phys. Chem. B 112 (2008) $15327-15332$

[18] Y. Kusumoto, M. Shizuka, Chem. Phys. Lett. 125 (1986) 64-68.

[19] R. Guo, X.J. Zhu, X. Guo, Colloid Polym. Sci. 281 (2003) 876-881.

[20] M.J. Frisch, G.W. Trucks, H.B. Schlegel, G.E. Scuseria, M.A. Robb, J.R. Cheeseman, G. Scalmani, V. Barone, B. Mennucci, G.A. Petersson, H. Nakatsuji, M. Caricato X. Li, H.P. Hratchian, A.F. Izmaylov, J. Bloino, G. Zheng, J.L. Sonnenberg, M. Hada, M. Ehara, K. Toyota, R. Fukuda, J. Hasegawa, M. Ishida, T. Nakajima, Y. Honda, 0. Kitao, H. Nakai, T. Vreven, J.A. Montgomery Jr., J.E. Peralta, F. Ogliaro, M. Bearpark, J.J. Heyd, E. Brothers, K.N. Kudin, V.N. Staroverov, R. Kobayashi, J. Normand, K. Raghavachari, A. Rendell, J.C. Burant, S.S. Iyengar, J. Tomasi, M. Cossi, N. Rega, J.M. Millam, M. Klene, J.E. Knox, J.B. Cross, V. Bakken, C. Adamo, J Jaramillo, R. Gomperts, R.E. Stratmann, O. Yazyev, A.J. Austin, R. Cammi, C. Pomelli, J.W. Ochterski, R.L. Martin, K. Morokuma, V.G. Zakrzewski, G.A. Voth, P. Salvador, J.J. Dannenberg, S. Dapprich, A.D. Daniels, Ö. Farkas, J.B. Foresman, J.V. Ortiz, J. Cioslowski, D.J. Fox, Gaussian 09, Revision A.1, Gaussian, Inc., Wallingford, CT, 2009.

[21] NIST Computational Chemistry Comparison and Benchmark Database, NIST Standard Reference Database Number 101, in: Russell D. Johnson III (Ed.), NIST Computational Chemistry Comparison and Benchmark Database, 2015. Release 17b, September, 2015 http://cccbdb.nist.gov/.

[22] Mathematica ${ }^{\mathbb{B}}$, Version 10.2.0.0, Platform Mac OS X, Wolfram Research Inc. Champaign, Illinois, 2010.

[23] D.M. Carey, G.M. Korenowski, J. Chem. Phys. 108 (1998) 2669-2675.

[24] M.R. Walrafen, M.S. Fisher, J. Chem. Phys. 85 (1986) 6970-6982.

[25] Q. Wan, L. Spanu, G.A. Galli, F. Gygi, J. Chem. Theory Comput. 9 (2013) 4124 4130 .

[26] Z. Wang, A. Pakoulev, Y. Pang, D.D. Dlott, J. Phys. Chem. 108 (2004) 9054-9063.

[27] Q. Sun, Vib. Spectrosc. 51 (2009) 213-217.

[28] Handbook of Chemistry and Physics on CD-ROM, Version 2011, in: W.M Haynes (Ed.), CRC Press, Taylor and Francis Group, 2011

[29] O. Sun, C. Oin, Chem. Geol. 283 (2011) 274-278.

[30] T. Azbej, M.J. Severs, B.G. Rusk, R.J. Bodnar, Chem. Geol. 237 (2007) 255-263.

[31] J. Wu, H.F. Zheng, Chem. Geol. 273 (2010) 267-271.

[32] R.N. Favors, Y. Jiang, Y.L. Loethen, D. Ben-Amotz, Rev. Sci. Instrum. 76 (2005) 033108.

[33] R.L. McCreery, Photometric standards for Raman spectroscopy, in: J.M. Chalmers, P.R. Griffiths (Eds.), Handbook of Vibrational Spectroscopy, John Wiley \& Sons Ltd., Chichester, 2002.

[34] K.M. Parker, A.M. Stalcup, J. Chromatogr. A 1204 (2008) 171-182.

[35] M.M. Meier, M.T.B. Luiz, P.J. Farmer, B. Szpoganicz, J. Incl. Phenom. Mol Recognit. Chem. 40 (2001) 291-295.

[36] R.I. Gelb, L.M. Schwartz, J. Incl. Phenom. Mol. Recognit. Chem. 7 (1989) 465476. 